University of Massachusetts Amherst

ScholarWorks@UMass Amherst

Travel and Tourism Research Association: Advancing Tourism Research Globally

\title{
The Changing Distribution of Global Tourism: Evidence from Gini Coefficients and Markov Matrixes
}

R. Geoffrey Lacher

Department of Parks, Recreation and Tourism Management Clemson University

Follow this and additional works at: https://scholarworks.umass.edu/ttra

Lacher, R. Geoffrey, "The Changing Distribution of Global Tourism: Evidence from Gini Coefficients and Markov Matrixes" (2016). Travel and Tourism Research Association: Advancing Tourism Research Globally. 7.

https://scholarworks.umass.edu/ttra/2010/Oral/7

This is brought to you for free and open access by ScholarWorks@UMass Amherst. It has been accepted for inclusion in Travel and Tourism Research Association: Advancing Tourism Research Globally by an authorized administrator of ScholarWorks@UMass Amherst. For more information, please contact scholarworks@library.umass.edu. 


\title{
The Changing Distribution of Global Tourism: Evidence from Gini Coefficients and Markov Matrixes
}

\author{
R. Geoffrey Lacher \\ Department of Parks, Recreation and Tourism Management \\ Clemson University
}

\begin{abstract}
This study measures the degree of dispersion of global tourism over the past two decades and then predicts the future dispersion of global tourism. Gini coefficients are used to measure the dispersion of international tourism arrivals and are calculated over the last 20 years using data from the UNWTO. The Gini coefficient is found to be decreasing over time, with time explaining a vast majority of the variance $\left(R^{2}=0.959\right)$. Using the same data, Markov transition matrixes are used to predict the future distribution of tourism based on changes in the distribution of tourism over the past 20 years.
\end{abstract}

Keywords: international tourism arrivals, Gini coefficient, secondary data.

\section{INTRODUCTION}

In 2008 there were nearly one billion international tourist arrivals across the globe (UNWTO 2009a). Until the recent global economic downturn, the tourism industry was growing at an annual rate of seven percent a year, and the United Nation's World Tourism Organization (UNTWO) expects continued rapid growth in the future, with international tourists arrivals reaching 1.6 billion in 2020 (UNWTO 2009a). These tourists represent the potential to create accelerated economic growth and their spending is more than $6 \%$ of total worldwide exports of goods and services. Large developed countries such as the United States ( $\$ 82$ billion), Spain ( $\$ 48$ billion), and Australia (\$16 billion) (UNWTO 2009a) received receipts well into the billions of dollars. Developing countries lag behind these figures, but still receive immense benefits. In 2005, the WTO estimated that international tourists spent \$333 billion in the developing world (UNWTO, 2005) and that "tourism was the primary source of foreign exchange earnings in the 50 least developed countries” (UNWTO, 2007:4). Such expansions, actively promoted by the WTO, make contributions in "poverty alleviation, economic growth, [and] sustainable development” (UNWTO, 2005:1) especially in countries in the developing world which often have fewer alternative options to generate significant income. While the developing world currently accounts for less than $3 \%$ of international tourism arrivals and tourism receipts, this figure is expanding faster in the developing world than in the developed world (UNWTO 2009a).

Current research suggests that countries with large tourism sectors are growing faster than those less involved with tourism (Brau, Lanza \& Pigliaru, 2003), and that the tourism industry is responsible for this economic development rather than vice versa (Brau, Lanza \& Pigliaru, 2007). Given the importance of tourism to countries' economies, it is important that we are able to understand the future distribution of tourism across the globe. While international tourist arrivals appear certain to increase at a fast rate for the foreseeable future (UNWTO 2009a), the geographical distribution of these 
tourist arrivals is less certain. While numerous articles have tracked the rise and fall of international tourists arrivals to various tourism destinations, countries, or continents ((Bonham, Edmonds, \& Mak, 2006, Brau, Lanza \& Pigliaru, 2003), global trends in the dispersion of tourism across countries have not been well examined.

While seemingly academic, this issue of the changing distribution of international tourism arrivals has practical implications. An increase in the dispersion of tourism arrivals would indicate that in the long term, tourists do seek authenticity and will attempt to escape crowds. This would mean that the national tourism destinations can only grow so much and tourism is ultimately limited as an engine of economic growth as tourists will seek out new, less crowded destinations. Conversely, countries with few tourist arrivals may see strong potential for growth based simply on the idea that they are less touristy and more exotic.

This study reviews theories and literature that would suggest why international tourist arrivals would become more widely and evenly dispersed over time, then uses Gini coefficients to measure the degree to which global tourism numbers have dispersed over the past two decades, and finally predicts what the future dispersion of global tourism will resemble using Markov transition matrixes in a technique first outlined by Quah (1993) in his study of global economic development.

\section{REASONS FOR AN INCREASING DISPERION IN GLOBAL TOURISM}

A number of other scholars have presented theories and evidence that there may be limits to the growth of tourism destinations. The famed geographer Walter Christaller noted that tourism was the one industry that did not seem to cluster and agglomerate, stating that "[t]ourism is drawn to the periphery of settlement districts as it searches for a position on the highest mountains, in the most lonely woods, along the remotest beaches. Here one may find, easier than elsewhere, the chance of recreation and sport" (Christaller, 1964 p.1056). Christaller's argument is that the spatial disposition of tourists is dictated by the psychological disposition of tourists. This psychological disposition towards the exotic and remote has been explored by authors such as MacCannell (1973). In his influential article on authenticity in tourism, he notes that "[s]ightseers are motivated by a desire to see life as it is really lived, even to get in with the natives, and, at the same time, they are deprecated for always failing to achieve these goals” (p.592) He believed that tourists are driven by a desire to find authenticity in their destination. This means gaining access to the "back" regions of the destination where real experiences occur instead of the "front" regions which are prepared especially for tourists. The term 'tourist' is increasingly used as a derisive label for someone who seems content with his obviously inauthentic experiences” (p. 592). The extension of this idea is that tourists will seek to get away from areas that are too "touristy" and go to areas that are less visited, and thus disperse tourism more evenly across space. This drive to get away from crowds results in the type of exploration and backpacker tourism described by Cohen (2004). The explorer's mentality has been noticed by tourism promoters and campaigns such as "unseen Thailand" (Chettamart, 2003) promote the less visited (or less spoilt) destinations, ironically likely leading them to be spoilt in the future.

Butler (1980) made a similar argument in his tourism area life cycle (TALC) model. This is a largely linear model in which a destination's arrivals grow quickly in a "development" stage, slowly in the "consolidation" stage, and plateau in the "stagnation" 
phase. Stagnation occurs as the capacity levels are met and the area falls out of fashion in general. From here the model becomes non-linear and predicts that the destination may "rejuvenate" and grow or "decline" and shrink, stating that destinations "should be viewed and treated as finite and possibly nonrenewable resources” (p.11). Empirically, numerous resorts have been found to be in the decline stage of the TALC model (Lagiewski, 2006). This decline might be cause by environmental degradation (Meyer \& Arendt, 1985), core-periphery relationships (Oglethorpe 1984; Keller 1987), or a general falling out of favor. This tendency toward decline contrasts with the idea of clusters forming a sustained comparative advantage. If popular destinations are destined to stagnate, a divergence cannot occur.

Healy (1994) takes a largely economic/anthropology view of the issue and argues that tourism landscapes are common pool resources which are subject to congestion. Too many tourists create long lines and crowds that block views and generally ruin the tourism experience. In addition to this psychological crowding, these tourists may degrade the physical quality of the resource. Too many tourism related business may move in and detract from the tourist landscape, degrade whatever comparative advantage they have and ultimately lead to slower growth of the tourism industry. In a stated preference choice modeling-based survey of tourism demand, Brau (2008) found that the risk of overcrowding was one of the most important features of destinations for prospective tourists, even more important than the variety of recreation opportunities available or the proximity of the main attraction.

A number of theories might be used to predict the opposite result, that tourism would become less evenly dispersed overtime and instead cluster in select countries. These theories are typically based around the idea of increasing competitive advantage, and include economic growth models such as the Lucas's (1988) which assert that countries gain more competitive advantage over time as industries innovate and become more efficient. He posits that countries have initial endowments that create comparative advantage in certain industries, and that businesses become more adept at these industries by learning over time, the comparative advantages may increase. The diamond model created by Porter (1990), argues that comparative advantage not only lies in natural endowments, but also in the social links and experience that can be gained by industry clusters over time. Porter argues that nations or regions can, through experience, continually improve and produce new innovations that can increase the competitive advantage and lead to a permanent competitive advantage. One way of doing this is by forming business clusters over time which consists of linked firms, often in different sectors which increase efficiency and innovation (Porter 1990). Rivalry between domestic firms can also stimulate innovation and further competitive advantage. High demand can also create specialized inputs and infrastructure. Porter (1990) even used a tourism example, citing the manner in which the Napa Valley wine cluster and tourism cluster form a symbiotic relationship and promote one another.

\section{METHODS}

To determine the degree to which tourist arrival numbers have dispersed or clustered in the past and estimate whether this trend will continue in the future, two techniques are employed on two different sets of data. The two data sets are the historical tourist arrivals in individual countries as calculate by the UNTWO, and those 
same arrivals divided by the countries size in square miles. It was also desired to control of the size of the countries in the analysis, so the Gini coefficient for the inequality of tourist arrivals per square mile of land (or tourist arrival density) were also calculated for every country.

This first technique involves calculating the Gini coefficients for international tourist arrivals and tourist arrival density across all countries for the five years currently available on the UNWTO website, 1990, 1995, 2000, 2003, and 2004. To predict the future distribution of tourism across all countries, this paper will use the methodology outlined by Quah (1993). This involves placing countries into groups according to the numbers of tourist arrivals they received in 1990 and 2000, and tracking the movement of countries from one group to another. A Markov chain transition matrix is then used to estimate the future distribution of tourist arrivals. This technique will also be performed on both data sets. World tourism arrivals were gathered from the UNWTO (UNWTO 2009b) and the size of the countries was collected from the CIA World Factbook (Central Intelligence Agency, 2009).

\section{Gini coefficient}

The Gini coefficient is a frequently used measure of inequality, and is equal to the ratio of the difference between a number set's Lorenz curve and line of perfect equality and the total area under the line of perfect equality. The Lorenz curve shows the relationship between the cumulative percentage of numbers when the numbers are arranged in ascending order. For our purposes, the x-axis of the Lorenz curve is the cumulative percentage of the countries in the sample (arranged from least to most visited or visitation per square mile) and the y-axis represents the cumulative percentage of number of tourists to these countries (see Figure 1). The Gini coefficient can range from 0 to 1 with 0 representing perfect equality and 1 representing perfect inequality. It is most commonly used to measure income inequality but has been used in numerous applications including application in tourism research such as quantifying seasonality (Fernadez-Morales, 2003) and industry agglomeration (Urtasun \& Gutierrez, 2006).

The number of international tourist arrivals to individual countries was gathered from the UNWTO website (2009b) for the years 1900, 1995, 2000, 2003, and 2004, which are all the years currently available. Every country with data for all 5 years was included in the initial sample $(n=147)$. A sample of 143 countries was used to calculate the Gini coefficient for total arrivals per square mile. Four countries (Macau, Monaco, St. Maarten, and Bermuda) were eliminated due to both their small size leading to an extremely large arrival per square mile figures which exerted undue influence on the Gini coefficients numbers and, in some cases, their questionable status as independent countries. The Gini coefficients for tourist arrivals and tourist arrival density were calculated for these 5 samples using the trapezoidal method (equation 1) in which $\mathrm{X}_{k}$ represents the cumulative proportion of the counties and $\mathrm{Y}_{k}$ represents the cumulative proportion of tourists arrival (again where the countries are arranged in ascending or

$$
G_{1}=1-\sum_{k=1}^{n}\left(X_{k}-X_{k-1}\right)\left(Y_{k}+Y_{k-1}\right)
$$


An OLS regress was performed to test whether "years since 1990" is a significant predictor for the Gini coefficient for number of arrivals and arrival density.

\section{Markov matrix}

This section follows the methodology first outlined by Quah (1993) in his oftcited article "Empirical Cross-Section Dynamics in Economic Growth". The goal is to use the observed changes in the distribution of tourists throughout the world in the 14 year period (1990-2004) to predict the distribution of tourists in the future and then predict the equilibrium state. This is done by using Markov transition matrix, the basics of which will be quickly reviewed.

In a matrix with $n \times \mathbf{1}$ vectors, $F_{t}$ represents the distribution at time $t$, with $n$ states. In this case, each state will represent an interval of tourist arrivals (or tourist arrival density) when compared to the world average (these will be called "bins"). $M$ represents the $(n \times n)$ Markov transition matrix governing the transformation of $F_{t}$ into $F_{t+1}$. For example, if n equals 3 the Markov matrix will be

$$
M=\left(\begin{array}{lll}
a_{11} & a_{12} & a_{13} \\
a_{21} & a_{22} & a_{23} \\
a_{71} & a_{72} & a_{72}
\end{array}\right)
$$

Where each element of the matrix $a_{j k}$ gives the probability of transition from state $j$ in the initial period to state $k$ during the next period, the transition from $F_{t}$ into $F_{t+1}$ is therefore

$$
F_{t} \bullet M=F_{t+1}
$$

Assuming that the conditions of the Markov transition probabilities remain constant over time, this process can be iterated over $s$ times as follows

$$
F_{t}^{\prime} \cdot M^{S}=F_{t 1 g}^{\prime}
$$

This process can be iterated until $s$ reaches infinity so that we may predict the future steady state distribution of $\bar{F}$ thusly

$$
F_{Q+2}=M^{2}+F^{g+\infty} \rightarrow F^{n}
$$

For this paper's purpose, a $\bar{F}$ tending towards a distribution that somewhat resembles a normal distribution would indicate an even dispersion of tourism arrival numbers, while a bimodal distribution would indicate clustering. To derive $\bar{F}, M$ must first be determined. To do this Quah's (1992) methodology was followed. This involves sorting countries in bins of similar tourist arrivals (and arrival densities) based on their comparison to the world average. Sorting the countries into bins was initially problematic due to the heavily skewed nature of the distribution. This issue was resolved by taking the log of tourist arrivals and log of tourist arrivals per square mile. These numbers were divided by the average log of tourist arrivals and the average log of tourist arrivals per square mile and then sorted into five bins. 
Each country's tourist arrivals relative to the world average were divided into intervals at $0.7,0.9,1.1$, and 1.3 and tourist arrival density relative to the world average were divided into intervals at $(-0.2), 0.5,1.5$, and 2.5 . These numbers make the groups roughly even in size in year 1990. Tables 1 and 2 show the distribution of the countries in 1990 and 2004. The movement of every country between the two years was tracked in regards to what bin it was in in 1990 and the bin it was in 2004. Tracking these movements revealed the probability of moving between different bins, which is shown in Tables 3 and 4.

\section{Table 1}

The Distribution of Countries Arranged into Bins by the Log of Their Total Annual International Tourist Arrivals when Divided by the World Average

\begin{tabular}{lcc}
\hline Bin Range & 1990 & 2004 \\
\hline$<0.7$ & 31 & 25 \\
\hline $0.7-0.9$ & 28 & 34 \\
\hline $0.9-1.1$ & 37 & 32 \\
\hline $1.1-1.3$ & 22 & 28 \\
\hline$>1.3$ & 29 & 28 \\
\hline
\end{tabular}

Table 2

The Distribution of Countries Arranged into Bins by the Log of Their Total Annual International Tourist Arrivals per Square Mile when Divided by the World Average

\begin{tabular}{lcc}
\hline Bin Range & 1990 & 2004 \\
\hline$<-0.2$ & 27 & 16 \\
\hline$-0.2-0.5$ & 30 & 31 \\
\hline $0.5-1.5$ & 33 & 49 \\
\hline $1.5-2.5$ & 26 & 36 \\
\hline$>2.5$ & 27 & 11 \\
\hline
\end{tabular}

Table 3

The Markov Matrix for Total Annual International Tourist Arrivals.

\begin{tabular}{ccccccc} 
& & \multicolumn{5}{c}{ To Bin } \\
& & 1 & 2 & 3 & 4 & 5 \\
\cline { 2 - 7 } & 1 & 0.677 & 0.323 & - & - & - \\
\multirow{4}{*}{ From } & 2 & 0.107 & 0.607 & 0.286 & - & - \\
Bin & 3 & - & 0.243 & 0.595 & 0.162 & - \\
& 4 & 0.045 & - & 0.091 & 0.773 & 0.091 \\
& 5 & - & - & - & 0.103 & 0.897 \\
\hline
\end{tabular}


Table 4

The Markov Matrix for Total Annual International Tourist Arrivals per Square Mile

\begin{tabular}{cc|cccccc} 
& & \multicolumn{5}{c}{ To Bin } \\
\cline { 3 - 8 } & 1 & 1 & 2 & 3 & 4 & 5 \\
\hline \multirow{2}{*}{ From } & 2 & 0.78 & 0.22 & - & - & - \\
Bin & 3 & 0.03 & 0.63 & 0.33 & - & - \\
& 4 & - & 0.06 & 0.91 & 0.03 & - \\
& 5 & - & - & 0.31 & 0.69 & - \\
& 5 & - & - & - & 0.59 & 0.33 \\
\hline
\end{tabular}

Tables 4 and 5 therefore represent $M$ and enable us to calculate $\bar{F}$ While the process of finding the equilibrium of the Markov transition Matrix is ergodic (not dependent on initial conditions), the distribution from 2004 is used as $\bar{F}$ so that we can approximate the number of periods (years) between the present distribution and $\bar{F}$ for both total international arrivals and arrival density. Once the numbers have made their final change on the integer level the distribution will be considered to be at $\bar{F}$.

\section{RESULTS}

\section{Descriptive statistics}

The sample of 147 countries used to calculate the Gini coefficient for total arrivals had a mean of 2,471,000 (SD = 7,075,000) in 1990 and 4,111,000 $(\mathrm{SD}=10,327,000)$. While not the primary focus of our study, it should be noted that both the skewness and kurtosis measures decrease from 1990 to 2004, from 4.66 to 4.33 and from 24.63 to 21.64 respectively, indicating a tendency towards an even dispersion. In 1990, the mean tourist arrival for the sample of 143 countries was 178 tourist arrivals per square miles $(\mathrm{SD}=501)$, and in 2004 the mean was $255(\mathrm{SD}=680)$. Again, both the skewness and kurtosis measures decrease from 1990 to 2004, from 4.38 to 4.00 and from 21.16 to 16.89 respectively, indicating a tendency towards even dispersion.

\section{Gini coefficients}

The results for the Gini coefficient for total arrivals showed a dispersion of tourist arrivals, with the Gini coefficient decreasing steadily from approximately 0.838 in 1990 to 0.810 in 2004 (Figure 1). OLS regress showed that "Years since 1990" was a significant factor in predicting the Gini coefficient $(\mathrm{p}<0.01)$ and explained the vast majority of the variance $\left(\mathrm{R}^{2}=0.959\right)$. The coefficients indicate that the Gini coefficient is decreasing by 0.0018 per year on average. 


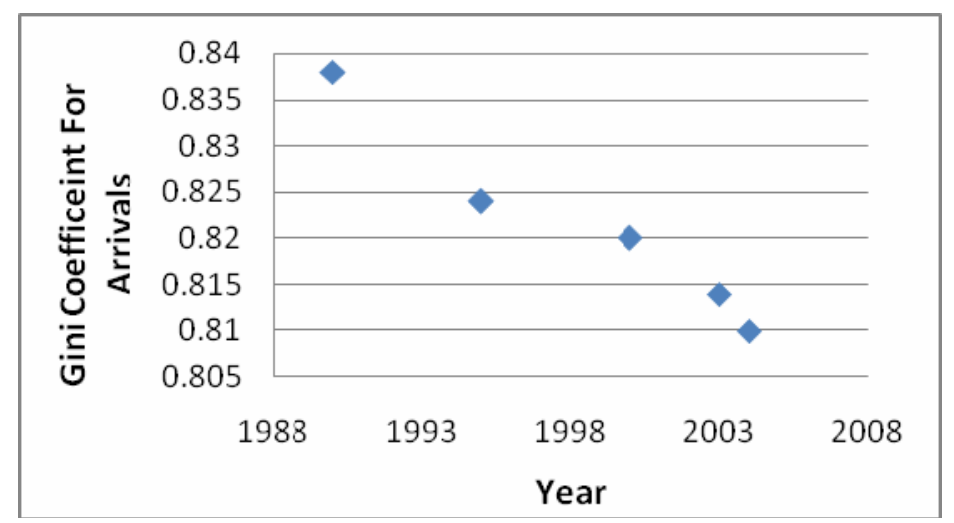

Figure 1: The Gini Coefficient for Total International Tourist Arrivals over Time

The results for the Gini coefficient for total arrivals per square mile also showed a dispersion of tourist arrivals, with the Gini coefficient again decreasing steadily from approximately 0.885 in 1990 to 0.855 in 2004 (Figure 2). OLS regress showed that "Years since 1990" was a significant factor in predicting the Gini coefficient $(\mathrm{p}<0.001)$ and explained a vast majority of the variance $\left(\mathrm{R}^{2}=0.989\right)$. The coefficients indicate that the Gini Coefficient is decreasing by 0.0022 per year on average. These results, through their similarity, the strength of their significance, and the high percentage of variance that they explain, indicate that tourism arrivals numbers are tending towards an even dispersion, and that the spatial distribution of tourists is becoming more evenly dispersed over time.

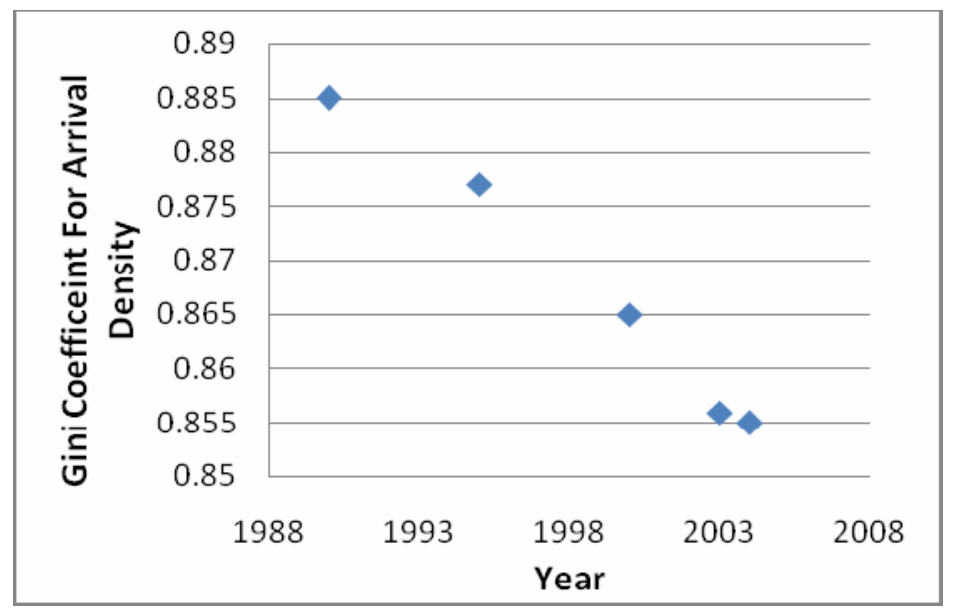

Figure 2: The Gini Coefficient for Total International Tourist Arrivals per Square Mile over Time

\section{Markov matrix}

Before discussing the equilibrium states, a quick review of Tables 6 and 7 allows one to observe how tourist numbers have changed in the past 14 years. For the tourist arrival figures we can note decreases in bins 1, 3, and 5 (though only a decrease of 1 country in bin 5) with increases in bins 2 and 4 . Overall it is hard to draw any conclusion from this pattern. It does indicate that the observed decrease in the Gini coefficient was most likely caused by an increase of tourist arrivals in the less popular countries. For the tourist arrival density figure, there is a major decrease in bins 1 and 5 along with major increases in bins 3 and 4, and a slight increase in bin 2. These results are very consistent 
with the change in the Gini coefficient as the number of countries with arrival densities far from the average has decreased while the numbers closer to the average have increased.

\section{Table 1}

The Equilibrium Distribution of Total International Tourism Arrivals and Total International Tourism Arrivals per Square Mile

\begin{tabular}{cccc} 
& Total & \multicolumn{2}{c}{ Per Square Mile } \\
\hline Bin & Number of Countries & Bin & Number of Countries \\
\hline 1 & 16 & 1 & 3 \\
\hline 2 & 32 & 2 & 19 \\
\hline 3 & 31 & 3 & 105 \\
\hline 4 & 37 & 4 & 10 \\
\hline 5 & 32 & 5 & 0 \\
\hline
\end{tabular}

The Markov chain for total arrivals reached an equilibrium not dissimilar from the present day distribution. The model shows no strong dispersion or clustering, and took 60 iterations to reach equilibrium. The main difference when compared to today's figure is the decrease in the number of countries in the lowest bin, moving from 25 in 2004 to 16 at the equilibrium. The Markov chain for total arrivals per square mile showed a strong tendency towards dispersion. The model took only 20 iterations to reach equilibrium and shows a markedly different distribution than the current world distribution. 105 out of 143 countries end up in bin 3, indicating that most of the world has a tourist arrivals per square mile figure close to the world average. In this predicted equilibrium tourist arrivals per square mile are fairly evenly distributed throughout the entire world.

\section{DISCUSSION AND CONCLUSION}

As a whole, the results indicate the world tourism arrivals have converged and will continue to converge, at least in terms of density, in the future. The quick dispersion shown in the Markov Chain Matrix for tourist arrivals per square mile is consistent with the results from the Gini coefficient analysis. This dispersion supports the hypothesis that tourists ultimately desire to go to places that are less touristy in search of authentic destinations. The equilibrium results from the Markov Matrix for total tourist arrivals do not display a strong trend towards dispersion, though they are closer to an even dispersion than their present distribution. This might indicate that tourists may be more sensitive to the density of tourists than the total number of tourists in a country.

Theoretically, these results indicate that tourists desire to explore more authentic and less touristy destinations is stronger than countries ability to use economies of scale and strong clusters to further their comparative advantage. Rather, it seems that having popular destinations actually becomes a disadvantage as tourists seek out novel and authentic experiences. Extending these lessons out to their extreme yields peculiar implications. If, as the regression analysis Markov chain for tourism arrival density indicates, tourism arrivals are quickly trending towards a relatively even dispersion, do 
the countries with few tourist arrivals need to concern themselves with tourism promotion? It seems that the desire to escape the touristy destinations may be enough of a driving force to pull tourists to the less crowded countries.

Interestingly, the September $11^{\text {th }}$ terrorist attack, which is frequently cited as having a strong influence on international tourism (Bonham, Edmonds, \& Mak 2006), does not seem to have affected the trend towards dispersion. One may have expected tourists to avoid more exotic (i.e. less visited) in favor of the more familiar destinations such as Western Europe. However, our results indicate no change in the trend towards an even distribution. Indeed perhaps the most surprising result is the remarkable consistency of the changes in dispersion, as both $\mathrm{R}^{2} \mathrm{~s}$ are higher than 0.95 . The period under review included two wars in Iraq, the early 90s global recession, the creation of the European Union, the East Asian Financial crisis, the dot-com boom and bust, and the September $11^{\text {th }}$ terrorist attack, none of which had an apparent major influence (either accelerating or decelerating) on the general trend toward dispersion. These results have important implications for tourism development. The dispersion of tourist arrivals indicates that countries with the relatively low tourist arrivals (or arrivals per square mile) have greater potential to grow the tourism industry faster. Therefore, countries that currently have low tourist arrivals should not ignore the industry, even if they do not believe they have the comparative advantage in tourism. Being less popular is actually a type of comparative advantage unto itself.

These results are relevant to development economics in that the majority of the counties with low tourist arrivals densities are less developed countries. For instance in 2004 the bottom ten countries in descending order in terms of arrivals per square mile were Bolivia, Mongolia, Bhutan, Ethiopia, Angola, Papua New Guinea, Mali, Democratic Republic of the Congo, Sudan, and Colombia. While the unpopularity of some of these countries is due to internal unrest or violence the bottom of the list is generally populated by poorer countries. These countries must realize that the relative paucity of tourists should, somewhat ironically, be seen as an indicator that the future growth potential is strong. And if their potential to increase tourism arrivals is strong their potential to grow the share that tourism contributes to the economy is also strong.

In the Markov chain simulation, countries with high tourists arrival densities are quickly brought back to the average, indicating there may ultimately be a limit to tourism's ability to drive an economy. Countries that are heavily dependent on tourism must be cognizant that countries currently on the higher end of the distribution should worry that their concentration of tourism is becoming a disadvantage. This may be of great concern as many of these countries are small island countries that depend heavily on tourism for foreign exchange and have relatively few other choices for economic development. They must work to maintain an image of being less touristy and more exotic both through advertising and management of tourism destinations, or examine other industries in which they might diversify in the future.

Finally, it should be noted that this study measures only international tourism arrivals. Given the growth of domestic tourism in some developing countries (Wen 1997), it is likely that the Gini coefficient for total tourism is declining even faster than the Gini coefficient for international tourism arrivals, and therefore is becoming an economic driver at a faster rate than in the developing world. 


\section{REFERENCES}

Brau, R. (2008) Demand-driven sustainable tourism? A choice modelling analysis. Tourism Economics. 14(4) 691-708.

Brau, R., Lanza, A. \& Pigliaru, F. (2007) How fast are small tourism countries growing? Evidence from the data for 19802003. Tourism Economics 13: 603-614.

Brau, R., Lanza, A., \& and Pigliaru, F. (2003) How Fast Are the Tourism Countries Growing? The Cross-country Evidence. FEEM Working Paper No. 85.

Bonham, C., Edmonds, C. \& Mak, J. (2006) The impact of 9/11 and other terrible global events on tourism in the United States. Journal of Travel Research. 45(1) 99-110.

Butler, R. W. (1980) The concept of a tourist area cycle of evolution: implications for management of resources. Canadian Geographer. 24(1) 5-12.

Central Intelligence Agency (2009) The World Factbook. Accessed online November 15 2009 at https://www.cia.gov/library/publications/the-world-factbook/index.html.

Chettamart, S. (2003) Ecotourism resources and Management in Thailand. A Paper presented at Malaysia-Thailand Technology and Business Partnership Dialogue. Langkawi, Malaysia.

Christaller, W. (1964) Some considerations of tourism location in Europe: The peripheral regions-under-developed countries-recreation areas. Papers in Regional Science 12(1) 95-105.

Cohen, E. (2004) “Toward a sociology of International Tourism”. In Tourism: The nature and structure of tourism Williams S. Ed. Taylor \& Francis. New York, New York.

Fernandez-Morales, A. (2003) Decomposing seasonal concentration. Annals of Tourism Research. 30(4) 942-956.

Healy, R. G. (1994) The" common pool" problem in tourism landscapes. Annals of Tourism Research. 21(3) 596-611.

Keller, C. P. (1987) Stages of peripheral tourism development-Canada's Northwest Territories. Tourism Management. 8(1) 20-32.

Lagiewski, R. M. (2006) "The application of the TALC model: a literature survey". in The Tourism Area Life Cycle Butler, R. ed. 27-50.

Lucas, R. E. (1998) On the Mechanics of Economic Development. Journal of Monetary Economics. 22(1) 3-42.

MacCannell, D. (1973) Staged authenticity: arrangements of social space in tourist settings. The American Journal of Sociology. 79(3) 589-603.

Meyer-Arendt, K. J. (1985) The grand Isle, Louisiana resort cycle. Annals of Tourism Research. 12(3) 449-465.

Oglethorpe, M. (1984) Tourism in Malta: a crisis of dependence. Leisure Studies. 3(2) $147-161$.

Porter, M.E. (1990) The Competitive Advantage of Nations. New York: Free Press.

Quah, D. (1993) Empirical cross-section dynamics in economic growth. European Economic Review. 37(2) 426-34.

Wen, Z. (1997) China's domestic tourism: impetus, development and trends. Tourism Management 18 (8): 565-571.

Urtasun, A. \& Gutiérrez, I. (2006) Tourism agglomeration and its impact on social welfare: An empirical approach to the Spanish Case. Tourism Management. 27(5) 901-912. 
UNWTO (2005) Declaration - Harnessing Tourism for the Millennium Development Goals. Accessed online November 15, 2009 at http://www.unwto.org/step/pub/en/pdf/declaration.pdf.

UNWTO (2007) ST-EP Programme. Accessed online November 15, 2009 at http://www.unwto.org/step/pub/en/pdf/step_prog.pdf.

UNWTO (2009a) World Tourism Barometer. Accessed online November 15, 2009 at http://www.unwto.org/UNWTOBarometer09.pdf.

UNWTO (2009b) International Tourist Arrivals \& Tourism Receipts by Country. Accessed online November 15, 2009 at http://www.world-tourism.org/facts/tmt.html. 